\title{
Farm Animal Protection Policy-Making and the Law: The Impetus for Change
}

\section{Introduction}

What should the role of government be in the protection of animals? There are two dimensions to this question. First, there is the normative issue of what obligations we owe to animals. The long-established ethic in Australian law is that of 'humane treatment'. This ethic accepts that animals have intrinsic worth, based on their cognitive capacities and/or sentiency, so that they are entitled to some protection. The line, however, is drawn at the point where protection of the interests of animals unacceptably interferes with human desires or interests. The validity of this ethic has been subjected to serious and persuasive critique. ${ }^{1}$ Despite this, it remains the dominant understanding of what we owe to animals, in the sense that it is entrenched in legislation around the country. ${ }^{2}$ However, even if this remains the prevailing, state-sanctioned ethic of protection, a second issue remains to be addressed - the government's role in coordinating the translation of this ethic into workable standards. This article focusses on this second issue.

Current protection approaches, especially in the area of farm animal protection, are marked by a closed standard-setting community, adoption of standards which allow for the widespread imposition of cruel practices, and minimal enforcement of even those low standards. Government is increasingly neglecting the animal protection regulatory sphere, leaving a space which is filled by a self-regulating industry, large retailers responding to consumer pressure, and non-government organisations (NGOs) seeking to incrementally improve minimum government standards. The state of animal protection policy-making, including standard-setting, is so dire that there is now some support across a significant portion of the political community for a revised approach, built around some form of independent statutory agency assuming responsibility for animal welfare matters. The standout exception to this broad political consensus is the "farmers' party", the National Party of Australia, and as a result, their coalition partner, the Liberal Party. This has created a political stale-mate, with even modest reform unlikely until there is a change in the current Federal Government.

The impetus for policy reform was given a major boost early in 2017 by an unlikely source. The Productivity Commission recommended the creation of an independent, federal statutory animal welfare agency as part of its wider inquiry into the state of Australian agriculture. ${ }^{3}$ The Commission recommended that a new Australian Commission for Animal Welfare assume responsibility for the development of national standards and guidelines for farm animal protection. The findings of the Productivity Commission did not come as a surprise to those who have been closely examining the farm animal standards process in Australia. They are consistent with the conclusions of research conducted on behalf of the Farm Animal

\footnotetext{
${ }^{1}$ See, eg, Robert Garner, Animal Ethics (Polity Press, 2005); Alex Bruce, Animal Law in Australia: An Integrated Approach (LexisNexis, $2^{\text {nd }}$ ed, 2017) chs $1 \&$ 2; Steven White, 'Exploring Different Philosophical Approaches to Animal Protection in Law' in Peter Sankoff, Steven White and Celeste Black (eds), Animal Law in Australasia: A New Dialogue (Federation Press, 2nd ed, 2013) ch 2.

${ }^{2}$ See generally Animal Welfare Act 1992 (ACT); Prevention of Cruelty to Animals Act 1979 (NSW); Animal Welfare Act (NT); Animal Care and Protection Act 2001 (Qld); Animal Welfare Act 1985 (SA); Animal Welfare Act 1993 (Tas); Prevention of Cruelty to Animals Act 1986 (Vic); Animal Welfare Act 2002 (WA)

${ }^{3}$ Productivity Commission, Regulation of Australian Agriculture (Report No 79, 15 November 2016).
} 
Institute, ${ }^{4}$ regulatory scholars, ${ }^{5}$ and animal protection NGOs such as Animals Australia, RSPCA Australia, Voiceless and World Animal Protection. ${ }^{6}$ This article explores problems underpinning standard-setting for the protection of farm animals in Australia which have provoked calls for change, and argues that the approach advocated by the Productivity Commission, while not a panacea, would be an important development in farm animal protection in Australia.

\section{The Legislative Regime for the Protection of Farm Animals}

The regulatory regime underpinning farm animal protection starts with state and territorybased animal protection legislation. Although there are differences in the detail, the general approach is to prohibit cruelty to animals and to include provisions imposing obligations on owners or those in charge of animals to provide for the needs of an animal. Queensland legislation, for example, prohibits cruelty under s 18(1) of the Animal Care and Protection Act 2001 (Qld) ('ACPA'). The cruelty standard generally does not apply in an unqualified way. So, for instance, s 18(2)(a) provides that cruelty includes causing an animal pain 'that, in the circumstances, is unjustifiable, unnecessary or unreasonable'. In New South Wales, any reference to cruelty includes a reference to an act that is 'unjustifiable, unnecessary or unreasonable', ${ }^{7}$ and there is a defence for various specific cruel practices so long as they inflict no 'unnecessary pain' on an animal. ${ }^{8}$ Most jurisdictions also have an aggravated animal cruelty offence. Again, to take Queensland as an example, s 242 of the Criminal Code (Qld) makes it an offence to intentionally inflict 'severe pain or suffering', to unlawfully kill, or cause 'serious injury or prolonged suffering to, an animal'.

Some jurisdictions have legislated an explicit duty of care, establishing positive obligations to provide for the needs of an animal. In Queensland, s 17 imposes a duty of care on those in charge of animals that is explicitly modelled on the Five Freedoms, a conception of animal welfare which emerged in the 1960s as a response to the increasing growth in intensive or factory farming of animals. ${ }^{9}$ Section 17 requires that a person in charge of an animal take reasonable steps to provide for an animal's needs for: appropriate food and water; accommodation or living conditions; display of normal patterns of behaviour; treatment of disease or injury; and handling. A duty of care approach has also been legislated in the ACT, the Northern Territory and Tasmania. ${ }^{10}$ Other jurisdictions include a range of separately

\footnotetext{
${ }^{4}$ Gaétane Potard, Designing Balanced and Effective Farm Animal Welfare Policies for Australia (Farm Animal Institute, April 2015).

${ }^{5}$ See, eg, Jed Goodfellow, 'Regulatory Capture and the Welfare of Farm Animals in Australia' in Deborah Cao and Steven White (eds), Animal Law and Welfare: International Perspectives (Springer International, 2016) 195; Elizabeth Ellis, 'Making Sausages and Law: The Failure of Animal Welfare Laws to Protect both Animals and Fundamental Tenets of Australia's Legal System' (2010) 4 Australian Animal Protection Law Journal 6.

${ }^{6}$ Animals Australia, 'What an Independent Office of Animal Welfare Would Mean for Animals' (1 August 2016)

$<$ http://www.animalsaustralia.org/features/independent-office-animal-welfare-2016.php>; RSPCA Australia, 'RSPCA Welcomes Proposal for an Australian Commission for Animal Welfare' (29 March 2017) $<$ https://www.rspca.org.au/mediacentre/news/2017/rspca-welcomes-proposal-australian-commission-animal-welfare>; Voiceless, 'Independent Office of Animal Welfare' (undated) <https://www.voiceless.org.au/content/independent-office-animal-welfare>; Dr Jennifer Ford, 'Advance Australian Animal Welfare: The Urgent Need to Re-establish National Frameworks' (World Animal Protection, 29 February 2016) $<$ https://www.voiceless.org.au/content/independent-office-animal-welfare $>$.

${ }^{7}$ Prevention of Cruelty to Animals Act 1979 (NSW) (POCTAA (NSW)) s 4(2).

${ }^{8}$ POCTAA (NSW) s 24 .

${ }^{9}$ For an account of the development of the Five Freedoms see David J Mellor and John R Webster, 'Development of Animal Welfare Understanding Drives Change in Minimum Welfare Standards' (2014) 33 Scientific and Technical Review 121; Clare McCausland, 'The Five Freedoms of Animal Welfare are Rights' (2014) 27 Journal of Agricultural and Environmental Ethics 649; Steven P McCulloch, 'A Critique of FAWC's Five Freedoms as a Framework for the Analysis of Animal Welfare' (2013) 26 Journal of Agricultural and Environmental Ethics 959.

${ }^{10}$ Animal Welfare Act 1992 (ACT) s 6B; Animal Welfare Act (NT) ss 7-8; Animal Welfare Act 1993 (Tas) s6.
} 
specified obligations. ${ }^{11}$ The Five Freedoms have been superseded in the animal welfare science literature by a focus on concepts such as the affective state of animals. ${ }^{12}$ These newer conceptions of animal welfare have yet to be reflected in legislation.

The cruelty prohibition and the duty of care or similar provisions nominally apply to all animals. However, perhaps the essential point to appreciate about the scope of animal protection legislation is that, ordinarily, the key protection standards do not apply to the vast majority of animals (ie farm animals). This is because all jurisdictions have exemptions or defences to prosecution where there is compliance with a farm animal code of practice. ${ }^{13}$ Again, while the details are slightly different across jurisdictions, the principle is generally the same: comply with a code of practice, and avoid prosecution for breach of the cruelty or duty standards. Victoria, unlike other jurisdictions, has specific livestock management legislation, but here the general operation of code exemptions applies in a similar way. ${ }^{14}$

The net result of this legislative structure is that codes of practice are key in understanding the extent of protection afforded to farm animals. If the standards included in codes of practice contemplate cruel practices, or practices otherwise inimical to the well-being of farm animals, there is unlikely to be any basis for a prosecution because of the statutory exemption. This raises important questions, including what practices are allowed by the codes and who creates the codes (ie who sets the acceptable minimum protection standards).

\section{Codes of Practice and Farm Animal Protection}

Codes of practice generally take the form of detailed regulations made, or adopted under, the primary animal protection statute. Where adopted under statute, compliance with the codes of practice ensures that some routine animal husbandry procedures, which might otherwise be characterised as cruel, are not legally actionable. Examples include the debeaking of chickens without pain relief; disbudding and dehorning of cows without pain relief; mulesing of sheep without pain relief; tail docking and teeth clipping of piglets without pain relief; and premature separation of the young from their mothers, including piglets and dairy calves, denying natural, maternal behaviours and causing separation distress. ${ }^{15}$ It should also be noted that while compliance with some codes may be mandatory under statute, others may only be voluntary. To complicate matters further, the balance between mandatory and voluntary codes varies from jurisdiction to jurisdiction. ${ }^{16}$

While codes of practice may be tabled in Parliament, as regulations they are generally subject to very little or no parliamentary scrutiny. This means that the issue of who authors the standards is very important. In Australia, both historically and under current processes, codes of practice are essentially made by those with a direct stake in the profitability of the agricultural sector - farm industry groups and agricultural departments.

\footnotetext{
${ }^{11}$ See, eg, Prevention of Cruelty to Animals Act 1979 (NSW) ss 8-9.

${ }^{12}$ See, eg, Donald M Broom, 'A History of Animal Welfare Science' (2011) 59 Acta Biotheoretica 121; David J Mellor and John R Webster, 'Development of Animal Welfare Understanding Drives Change in Minimum Welfare Standards' (2014) 33 Scientific and Technical Review 121.

${ }^{13}$ See, eg, Animal Care and Protection Act 2001 (Qld) ss 38, 40; Animal Welfare Act 1985 (SA) s 43.

${ }^{14}$ Livestock Management Act 2010 (Vic) ss 4(2) \& (3).

${ }^{15}$ See various Model Codes of Practice published by the CSIRO: CSIRO Publishing, Primary Industries Report Series

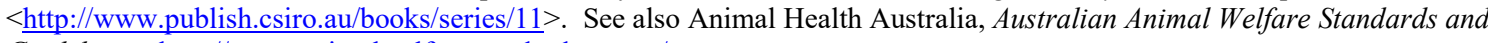
Guidelines $<$ http://www.animalwelfarestandards.net.au/>.

${ }^{16}$ For a detailed discussion see Arnja Dale and Steven White, 'Codifying Animal Welfare Standards: Foundations for Better Animal Protection or Merely a Façade?' in Peter Sankoff, Steven White and Celeste Black (eds), Animal Law in Australasia: Continuing the Dialogue (Federation Press, $2^{\text {nd }}$ ed, 2013) 151,
} 


\section{A. History of Codes of Practice}

Model Codes of Practice for animal welfare (Model CoPs) were first developed in Australia in the early 1980s, and later adopted under legislation in the states and territories. The initial development of Model CoPs was a response to increasing international attention on Australian farming practices and the continued growth of intensive farming. The initial process was spurred on by a shared consensus about the need for some national consistency in farm animal welfare standard-setting, reflected, for example, in recommendations from a Senate Select Committee on Animal Welfare. ${ }^{17}$

Over a period of 25 years 22 Model CoPs were produced under the auspices of the Primary Industries Ministerial Council (PIMC), comprised of Commonwealth, state and territory primary industries ministers, in turn relying on advice from a committee structure comprised of agriculture department officials, farm industry bodies and animal welfare science research bodies. The Model CoPs were adopted in different ways in different state and territory jurisdictions. Some jurisdictions adopted them in total, some in modified form, while others ignored them or developed their own codes.

\section{B. Codes and the Australian Animal Welfare Strategy}

The disparate approaches to the adoption of the codes led to widespread variation in the application of animal protection standards across Australia. In 2004 the Federal Government initiated the Australian Animal Welfare Strategy (AAWS). Notably, it was the treatment of Australian animals offshore that sparked this policy development:

Public outrage reached a fever pitch in 2003 with concern for the treatment of sheep destined for Saudi Arabia. This event became known as the "Cormo Express incident", named after the ship transporting the sheep. The media together with 14,000 letters to the Prime Minister, created a sense of urgency in the process. By July of that year (2003), the Federal Government began work on an Australian Animal Welfare Strategy in earnest. The strategy was pushed through until endorsed by all jurisdictions through the Primary Industries Ministerial Council in May 2004. ${ }^{18}$

The AAWS, led by the Federal Government, was designed to bring the states and territories together to establish a nationally consistent approach to standard-setting, especially in the area of farm animal welfare. A 2005 report commissioned by the Federal Government found a range of problems with the prevailing code development process. ${ }^{19}$ These included a failure to achieve national consistency, unclear purpose (regulatory standards or communication to producers), inconsistent application, uneven enforcement, lack of effective communication, and a lack of resources. There was also evidence that many producers ignored or did not have knowledge of the codes of practice.

Under the AAWS, a new standards development process was put in place. The AAWSsponsored approach involved the conversion of the Model CoPs to mandatory standards and advisory guidelines, with Animal Health Australia contracted to project manage this process.

\footnotetext{
${ }^{17}$ For an in-depth account see Dale and White, ibid.

${ }^{18}$ D Woodside, K Adams and J Trefry, Enhancing Collaboration for Australian Animal Welfare: Stage 1: Stakeholder Interviews (Report to AusWAC, July 2013), $9<$ http://www.australiananimalwelfare.com.au/content/enhancing-collaboration-stage-1stakeholderinterviews $>$

${ }^{19}$ Geoff Neumann and Associates, Review of the Australian Model Codes of Practice for the Welfare of Animals (Final Report, 9 February 2005)
} 
AHA is a not-for-profit consortium predominantly composed of industry representative groups and agricultural departments. ${ }^{20}$

The new standards development process was unquestionably more rigorous than the previous code development process. Submissions were invited on draft standards and made public. A regulatory impact statement was produced to explain proposed changes to standards, providing information on the relevant industry and a detailed cost-benefit analysis of various options. These sometimes included an account of the literature on relevant animal welfare science research. The progress of the development of standards and guidelines was publicly documented. This changed process, arguably, created the space for a public conversation about animal welfare. ${ }^{21}$

However, significant problems remained. The dominant stakeholders continued to be industry representatives and agricultural departments. Agricultural departments have a clear conflict - required to both administer animal protection legislation and at the same time engage in promotion of profitable agricultural sectors. ${ }^{22}$ The regulatory impact statement process undervalued animal protection, and was not responsive to consultation feedback. The use of animal welfare research science continued to be piece-meal, often poorly funded, and driven by an industry agenda, with defensive commissioning of research sometimes used to pre-empt issues likely to be raised by animal protection NGOs. ${ }^{23}$

The process of development of standards was also quite slow, with only one set of standards, those addressing land transport, completed and nationally adopted before the AAWS was axed by the Federal Government in late 2013. The AAWS was opportunistically cut by the National Party Agriculture Minister Barnaby Joyce as part of a wider government commitment to 'reducing red tape' ${ }^{24}$ Ending the AAWS has had a significant effect on the development of a national policy agenda in animal protection, even if the annual AAWS budget of around $\$ 1$ million was very small. RSPCA Australia pointed out that the cessation of the AAWS included winding back the supporting institutional structures, including 'the AAWS Advisory Committee and its working groups (including the Livestock \& Production Animals Working Group), effectively dismantling the framework and the process through which stakeholders engaged on a range of animal welfare issues and activities that allowed for animal welfare policy development in this country'. ${ }^{25}$

\section{Post-AAWS}

Some changes have been made since 2013, designed to streamline the process. Two further sets of standards, for cattle and sheep respectively, have been finalised, but not yet adopted

\footnotetext{
${ }^{20}$ Animal Health Australia, Members $<$ https://www.animalhealthaustralia.com.au/who-we-are/information-formembers/members/>.

${ }^{21}$ Peter Sankoff, 'The Animal Rights Debate and the Expansion of Public Discourse: Is it Possible for the Law Protecting Animals to Simultaneously Fail and Succeed?' (2012) 18 Animal Law 281.

${ }^{22}$ Goodfellow, above $\mathrm{n} 5$.

${ }^{23}$ Malcolm Caulfield, 'The Australian Animal Use Industry Rejects Anthropomorphism, But Relies on Questionable Science to Block Animal Welfare Improvements’ (2017) 6 Animal Studies Journal 155.

${ }^{24}$ For a close examination of the regulatory implications and ideological agenda of this campaign of 'deregulation' see Neil Gunningham, 'Two Cheers for Prescription? Lessons for the Red Tape Reduction Agenda' (2015) 38 University of New South Wales Law Journal 936.

${ }^{25}$ RSPCA Australia, 'Agricultural Competitiveness White Paper Submission' (IP635, 22 April 2014) 4

$<$ http://agwhitepaper.agriculture.gov.au/supporting-information/published-submissions-issue-paper $>$.
} 
under regulation by the states and territories. ${ }^{26}$ However, there is little evidence that much has changed since 2013 in terms of the key concerns highlighted above. The significant influence of industry interests in farm animal standard-setting processes has been further borne out in the development of a new free range poultry standard, recently adopted under Australian Consumer Law. ${ }^{27}$ After a series of successful Federal Court cases brought by the ACCC against producers making misleading claims about the welfare standards of their products, ${ }^{28}$ a national standard was developed and implemented which defines free range eggs as having been laid by hens with 'meaningful and regular access to the outdoors and with an outdoor stocking density of 10,000 hens per hectare or fewer' ${ }^{29}$ The figure of 10000 was the industry-preferred standard, rather than the 1500 included in the Model Code of Practice for Poultry. ${ }^{30}$ Importantly, the two dominant retailers in Australia, Coles and Woolworths supermarkets, had already adopted a lax free range standard, and this was used to underpin the egg industry's preferred definition. ${ }^{31}$ The standard has been criticised by animal advocacy groups ${ }^{32}$ and ridiculed by consumer organisation CHOICE as failing to accord with consumer perceptions of the meaning of free range. ${ }^{33}$

Private standard-setting schemes have also been developed in recent years, partly out of frustration with the slow development and/or inadequacy of government-sanctioned farm animal protection standards. First, industry has developed quality assurance schemes, usually as part of larger animal health schemes, designed to be privately audited and to at least meet the minimum-required government standards. ${ }^{34}$ These schemes have been formalised in Victoria in a form of shared regulation between the industry and government under specific legislation. ${ }^{35}$ Second, RSPCA Australia has developed its own set of evidence-based standards, going beyond minimum government standards. These have been adopted by large supermarket retailers such as Coles and Woolworths and incorporated into their supply chains. $^{36}$

To the extent these private schemes improve on the government-mandated minimum standards they are to be welcomed. However, animal welfare is a quintessential public policy

\footnotetext{
${ }^{26}$ See Animal Health Australia, above n 15, for a timeline. This leaves a significant number of Model CoPs yet to be converted to mandatory standards and advisory guidelines, including those addressing animals at saleyards, animals at slaughtering establishments, deer, buffalo, feral livestock, goats and rabbits.

${ }^{27}$ Australian Consumer Law (Free Range Egg Labelling) Information Standard 2017 (Cth). The Free Range Labelling Information Standard is not concerned with animal welfare per se, but with providing a meaning for the term 'free range' (ie a standard which must be complied with when eggs are marketed as free range). The standard is only mandatory for producers and retailers who choose to market their eggs as free range, leaving them free to continue marketing cage and barn-laid eggs. Separately, welfare standards and guidelines for poultry are currently being revised by Animal Health Australia: Animal Health Australia, "Animal Welfare Standards and Guidelines: Poultry' $<$ http://www.animalwelfarestandards.net.au/poultry/>.

${ }^{28}$ For an excellent summary of litigation in this area see Ian Weldon, 'Consumer Law and Animal Protection' (2014) 10 Australian Animal Protection Law Journal 4.

${ }_{29}$ Australian Consumer Law (Free Range Egg Labelling) Information Standard 2017 (Cth) s 7.

${ }^{30}$ Primary Industries Standing Committee, Model Code of Practice for the Welfare of Animals: Domestic Poultry (PISC Report 83 , 4th ed, 2004), $28<$ http://www.publish.csiro.au/Books/download.cfm?ID=3451 $>$. This Code is under revision: see above n 27.

${ }^{31}$ Rachel Carey, Christine Parker and Gyorgy Scrinis, 'Capturing the Meaning of "Free Range": The Contest between

Producers, Supermarkets and Consumers for the Higher Welfare Egg Label in Australia' (2017) 54 Journal of Rural Studies 266, 273.

32 RSPCA Australia, 'New Free Range Standard Will Not Meet the Needs of Consumers' (1 May 2017)

$<$ https://www.rspca.org.au/media-centre/news/2017/new-free-range-standard-will-not-meet-needs-consumers-rspca $>$; Humane Society International Australia, 'Consumers Duped with New Free Range Egg Standard' (27 April 2017)

$<$ http://www.hsi.org.au/go/to/2938/27th-april-consumers-duped-with-new-free-range-egg-standard.html\#.WebJLFtL-Hs $>$.

33 Tony Ibrahim, 'Shoppers Lose in New Free Range Egg Standard' (CHOICE, 26 April 2017) $<\underline{\text { https://www.choice.com.au/food- }}$ and-drink/meat-fish-and-eggs/eggs/articles/egg-standard-260417>

${ }^{34}$ Michelle K Edge, Paul H Hemsworth and John L Barnett, 'Verifying Legislative and Customer Requirements Utilising Animal Welfare Quality Assurance' (2008) 48 Australian Journal of Experimental Agriculture 1022.

${ }^{35}$ Livestock Management Act 2010 (Vic).

${ }^{36}$ RSPCA Australia, RSPCA Approved Farming $<$ https://rspcaapproved.org.au/>.
} 
issue and ought to be treated as such by government. Important questions about application, accountability and transparency are raised by private standard-setting schemes. As well, where private standards and compliance-checking are incorporated into co-regulatory schemes, such as the approach adopted in Victoria, the risk of regulatory capture is significant, where the regulator identifies more closely with the regulated than the public the regulation is designed to serve. ${ }^{37}$

\section{The Need for Reform}

There is, then, a very strong case to be made for reform of standard-setting processes for farm animal protection. Early in 2017 this was confirmed by the Productivity Commission in a report on the regulation of Australian agriculture. The Productivity Commission concluded that:

There is significant scope for greater rigour in the process of developing national farm animal welfare standards and guidelines. And importantly, for science and (soundly elicited) community values to play a more prominent role. Without reform, there is a risk that the agricultural sector and the Australian community will continue to face a patchwork of different regulatory arrangements across jurisdictions that do not rigorously take into account economic and social considerations. ${ }^{38}$

The Productivity Commission was very sensitive to the need for independence in developing farm animal standards, stating that:

There needs to be more independence in the standards development process so that outcomes are not overly influenced by the views of any one group, either industry or animal welfare groups. Judgments made to balance conflicting considerations should be transparent and apply rigorous scientific principles. Surveys of community values for animal welfare should be statistically robust and transparent. ${ }^{39}$

The Productivity Commission highlighted the New Zealand approach of establishing an independent statutory agency with expertise across a range of sectors, and an explicit requirement to consider both technical/scientific and ethical values in standard-setting. Ultimately, the Productivity Commission recommended the creation of an independent animal welfare agency in Australia, an Australian Commission for Animal Welfare. The Commission stated that an independent body would:

- provide greater independence in the standards development process, which would help ensure that standards provide a net benefit to the community.

- address concerns about potential conflicts of interest, particularly if the body was at arm's length from agriculture departments.

- enable trade-offs between competing interests and objectives to be made more independently.

- enable farm animal welfare regulation to be proactive, rather than reactive to incidents of mistreatment. ${ }^{40}$

Crucially, the Productivity Commission recognised the public importance of animal welfare regulation by recommending that the national body 'be funded by Commonwealth and state

\footnotetext{
${ }_{38}^{37}$ Arie Freiberg, Regulation in Australia (Federation Press, 2017) 120.

${ }^{38}$ Productivity Commission, above n 3, 228-9.

${ }^{39}$ Ibid 228.

${ }^{40}$ Ibid 232-3.
} 
and territory governments, not from industry or animal groups. This would help to ensure that the body is not unduly influenced by the positions of particular stakeholders'. ${ }^{41}$

The proposal put forward by the Productivity Commission would bring a greater degree of rigour to existing standard-setting processes for farm animal protection. However, it is notable that the Commission assumes the continued exploitation of farm animals for commercial gain, with the usual caveat that there is a need to balance 'independent scientific evidence on animal welfare, community values and costs to industry'. ${ }^{42}$ The need to 'balance' these interests is a common refrain in animal welfare policy, consistent with an underlying assumption that animals are due the limited protection of 'humane treatment'. ${ }^{43}$ To avoid re-producing the existing distortions in standard-setting, identified in Part III, future standard-setting processes should be open to different conceptions of the protection properly owed to farm animals.

\section{Conclusion}

The Productivity Commission's proposal for an independent agency addressing the regulation of animal welfare is not new, as noted in the Introduction to this article. The issue now is essentially one of political acceptance. There is evidence of a political shift in favour of reform. As long ago as 2003 then Senator Andrew Bartlett, of the Australian Democrats, introduced a bill seeking to establish a national office of animal welfare. ${ }^{44}$ More recently, in 2011, the Australian Labor Party (ALP) incorporated a commitment to an independent animal welfare agency into its national policy platform. ${ }^{45}$ Before losing office in 2013 the federal ALP Government pledged to introduce a bill which would have established an independent inspector-general of animal welfare and live exports. The Australian Greens support the creation of an independent animal welfare agency, and introduced a bill into the Senate in 2015 seeking to achieve this goal. ${ }^{46}$ In an effort to build wider federal parliamentary support for animal welfare reform, RSPCA Australia has recently established a Parliamentary Friends of the RSPCA group, co-chaired by a Liberal House of Representatives member and an ALP senator. ${ }^{47}$ Finally, in March 2015 Mark Pearson, representing the Animal Justice Party, was elected to the NSW Legislative Council. This was a highly significant political development in the area of animal protection. As Pearson pointed out in his inaugural speech, his successful candidature meant Australia was:

the second country in the world that has elected a Member of Parliament on [an animal protection] platform. The first country was Holland where, four years ago, Marianne Thieme of the Dutch Party for the Animals was elected to the Dutch Parliament. Since then, two others have joined her. New South Wales is the third jurisdiction in the world to have elected people to Parliament on the basis of animal protection and animal wellbeing. Last year the European Union elected two people, one from Germany

\footnotetext{
${ }^{41}$ Ibid 238.

42 Productivity Commission, above n 3, 237.

${ }^{43}$ According to this ethic, animals have some intrinsic worth and their interests are worthy of protection against gratuitous cruelty and neglect. Beyond this, though, animal interests may be routinely overridden by human interests, even where this involves significant harm. The norm of humane treatment has long underpinned animal protection legislation: see Steven White, 'Animal Protection Law in Australia: Bound by History' in Deborah Cao and Steven White (eds), Animal Law and Welfare - International Perspectives (Springer International, 2016) 109.

44 Andrew Bartlett, 'Animal Welfare in a Federal System: A Federal Politician's Perspective' in Peter Sankoff and Steven White (eds), Animal Law in Australasia: A New Dialogue (Federation Press, 1st ed, 2009) 376.

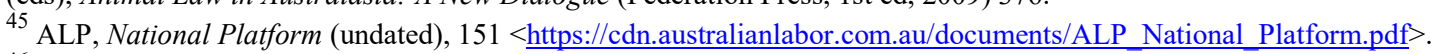

${ }^{46}$ Voice for Animals (Independent Office of Animal Welfare) Bill 2015 (Cth).

${ }^{47}$ RSPCA Australia, 'Friends in High Places' (5 September 2017) <https://www.rspca.org.au/media-centre/news/2017/friends-highplaces-rspca-establishes-parliamentary-friends-group-animal>; Parliament of Australia, Parliamentary Friendship Groups (NonCountry) (undated) $<$ https://www.aph.gov.au/About_Parliament/Parliamentary_Friendship $>$.
} 
and one from Holland, to the European Parliament on the platform of animal protection and wellbeing. $^{48}$

The current Federal Government's approach to agriculture is dominated by the parochial interests of the National Party, stifling the creation of an independent agency overseeing animal welfare. The momentum, however, is clearly shifting in favour of change. The Productivity Commission's report provides a very useful starting point for a more reformminded future government.

${ }^{48}$ NSW, Parliamentary Debates, Legislative Council, 6 May 2015, 139 (Mark Pearson). 